\section{Response to: 'Clinical benefit of vedolizumab on articular manifestations in patients with active spondyloarthritis associated with inflammatory bowel disease' by Orlando et al}

We thank Orlando et $a l^{1}$ for the critical appraisal of our paper. ${ }^{2}$ However, we believe that the limited sample size and the lack of sufficient follow-up do not support unmistakable evidence of clinical benefit of vedolizumab in spondyloarthritis (SpA). First of all, merely 36 out of 53 patients with inflammatory bowel disease (IBD) completed the 6-week induction phase at the last recorded observation, which makes the interpretation of data premature. Hence, as stated in our paper, mean time to flare in our patients was calculated at 64 days after the initiation of vedolizumab, ranging up to 114 days in these selected cases. The patients presented in the series from Orlando et al are also much older (mean 51.5 years vs 36.0 years) and display a higher rate of surgical intervention $(>60 \%)$ compared with our cases, which may respectively reflect a population less likely to develop SpA features and a disturbed gastrointestinal architecture in therapy-resistant patients. Similarly, no data on concomitant medication, which might be synergistic, are provided. Nevertheless, no induction or flare of SpA was seen in this small prospective cohort. This observation does not necessarily contradict with our case series, as the prevalence of these findings in clinical practice is currently unknown and should be further investigated.

Orlando et al do not report any induction or flare of $\mathrm{SpA}$ in their small prospective cohort, but go as far as suggesting a clinical benefit. However, less than half of patients of 14 active patients with SpA experienced a response, which was vaguely described as a 'sharp clinical benefit' at the level of the joint. Unfortunately, objective signs of disease activity and/or outcome measures such as MRI inflammation or imaging are lacking in the report, making the data difficult to interpret. Surprisingly, one of these six patients even responded well at the level of the joint, in absence of a gut response. Although we cannot exclude some efficacy, taking the high placebo response in $\mathrm{SpA}$ in up to $20 \%,{ }^{3} 4$ the follow-up time and the small sample size of this cohort into account, precaution is needed to make firm conclusions based on these results. In any case, the efficacy of vedolizumab in IBD-associated joint disease, if any, does not seem to measure up to the efficacy of anti-tumour necrosis factor reported previously in over $60 \%$ in IBD-related arthritis. ${ }^{5} 6$ The lack of mucosal vascular addressin cell adhesion molecule 1 (MADCAM-1) expression in synovial tissue despite the presence of $\alpha 4 \beta 7$ on synovial T cells in SpA, which contrasts with the gutspecific interaction with MADCAM-1, provides scientific rationale for a differential response on joint versus gut symptoms. ${ }^{78}$

In conclusion, the overall efficacy of vedolizumab in IBD-associated SpA remains unclear. The report of Orlando et al suggests some level of response in selected cases but the series is not sufficiently powered and the follow-up is too short in duration to permit firm conclusions on efficacy in SpA. It is clear that only placebo-controlled trials-and not cohort studies - will be able to address the remaining questions regarding the impact of vedolizumab in IBD-associated SpA.

\section{G Varkas, ${ }^{1,2} \mathrm{~F}$ Van den Bosch, ${ }^{1,2}$ D Elewaut ${ }^{1,2}$}

${ }^{1}$ Department of Rheumatology, Ghent University Hospital, Ghent, Belgium ${ }^{2}$ VIB Inflammation Research Centre, Ghent University, Ghent, Belgium

Correspondence to Dr D Elewaut, Department of Rheumatology, Ghent University Hospital, Ghent 9000, Belgium; dirk.elewaut@ugent.be

Contributors GV, FVdB and DE: study concept and design, analysis and interpretation of data, manuscript preparation and manuscript revision.

Competing interests None declared.

\section{Patient consent Obtained.}

Provenance and peer review Commissioned; internally peer reviewed.

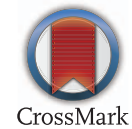

To cite Varkas G, Van den Bosch F, Elewaut D. Ann Rheum Dis 2017;76:e32.

Received 11 January 2017

Accepted 16 January 2017

Published Online First 9 February 2017

\section{SPlinked}

http://dx.doi.org/10.1136/annrheumdis-2016-211011

Ann Rheum Dis 2017;76:e32. doi:10.1136/annrheumdis-2016-211045

\section{REFERENCES}

1 Orlando A, Orlando R, Ciccia F, et al. Clinical benefit of vedolizumab on articular manifestations in patients with active spondyloarthritis associated with inflammatory bowel disease. Ann rheum dis 2017;76:e31.

2 Varkas G, Thevissen K, De Brabanter G, et al. An induction or flare of arthritis and/or sacroilitis by vedolizumab in inflammatory bowel disease: a case series. Ann Rheum Dis 2017;76:878-81.

3 Mease P, Sieper J, Van den Bosch F, et al. Randomized controlled trial of adalimumab in patients with nonpsoriatic peripheral spondyloarthritis. Arthritis Rheumatol 2015;67:914-23

4 Paramarta JE, De Rycke L, Heijda TF, et al. Efficacy and safety of adalimumab for the treatment of peripheral arthritis in spondyloarthritis patients without ankylosing spondylitis or psoriatic arthritis. Ann Rheum Dis 2013;72:1793-9.

5 Van den Bosch F, Kruithof E, De Vos M, et al. Crohn's disease associated with spondyloarthropathy: effect of TNF-alpha blockade with infliximab on articular symptoms. Lancet 2000;356:1821-2.

6 Herfarth $H$, Obermeier $F$, Andus $T$, et al. Improvement of arthritis and arthralgia after treatment with infliximab (Remicade) in a German prospective, open-label, multicenter trial in refractory Crohn's disease. Am J Gastroenterol 2002;97:2688-90.

7 Elewaut D, De Keyser F, Van Den Bosch F, et al. Enrichment of T cells carrying beta7 integrins in inflamed synovial tissue from patients with early spondyloarthropathy, compared to rheumatoid arthritis. J Rheumatol 1998;25:1932-7.

8 Salmi M, Rajala P, Jalkanen S. Homing of mucosal leukocytes to joints. Distinct endothelial ligands in synovium mediate leukocyte-subtype specific adhesion. J Clin Invest 1997;99:2165-72. 